\title{
Expression of miR-208b and miR-499 in Greek Patients with Acute Myocardial Infarction
}

\author{
KONSTANTINOS AGIANNITOPOULOS ${ }^{1}$, PANAGIOTA PAVLOPOULOU ${ }^{1}$, KONSTANTINOS TSAMIS ${ }^{2}$, \\ KONSTANTINA BAMPALI ${ }^{1}$, PINELOPI SAMARA ${ }^{1}$, GEORGE NASIOULAS ${ }^{3}$, \\ GEORGE MERTZANOS $^{2}$, DIMITRIOS BABALIS ${ }^{2}$ and KLEA LAMNISSOU ${ }^{1}$ \\ ${ }^{1}$ Division of Genetics \& Biotechnology, Department of Biology, National \& \\ Kapodistrian University of Athens, Athens, Greece; \\ ${ }^{2}$ Department of Cardiologic, "KAT" General Hospital, Athens, Greece; \\ ${ }^{3}$ GeneKor M.S.A, Athens, Greece
}

\begin{abstract}
Background/Aim: Certain microRNAs (miRs) present in human plasma are candidate biomarkers for cardiovascular diseases, including acute myocardial infarction (AMI). We examined the expression of two cardiac-specific miRs (miR-208b and miR-499) in a Greek pathological population. Materials and Methods: Plasma samples from AMI patients and healthy subjects (controls) were analyzed using TaqMan ${ }^{\circledR}$ MicroRNA assays. Results: The concentration of both miRs was significantly elevated in AMI patients compared to healthy controls. Moreover, receiver-operating characteristic (ROC) curve analysis showed that miR-208b and miR-499 displayed similar properties with the established AMI biomarker cardiac troponin T (cTnT). Conclusion: We showed, for the first time, that these miRs could be used as AMI biomarkers in our population as well. Our data are in agreement with those of studies based on different population groups and further strengthen the observation that plasma levels of circulating miR-208b and miR-499 could serve as potential AMI biomarkers.
\end{abstract}

MicroRNAs (miRs) are evolutionary small endogenous, noncoding, single-stranded RNAs involved in the regulation of gene expression at the post-transcriptional level (1). They possess an important role in multiple biological processes by

This article is freely accessible online.

Correspondence to: Konstantinos Agiannitopoulos, Division of Genetics \& Biotechnology, Department of Biology, National \& Kapodistrian University of Athens, 15784 Panepistimiopolis, Ilissia, Athens, Greece. Tel: +30 2107274636, Fax: +30 2107274318, e-mail: kagiannitopoulos@yahoo.gr

Key Words: Acute myocardial infarction, biomarkers, Greek population, microRNAs, plasma. binding to their target mRNAs and altering the protein expression of their candidate targets (2). Circulating miRs detected in serum or plasma, are actively secreted in macrovesicles or exosomes from different cell types (3), including cardiomyocytes. Elevated mRNA expression levels have been involved in numerous human pathologies including cardiovascular diseases (4).

Acute myocardial infarction (AMI) is the acute necrosis of myocardial tissue due to persistent and severe ischemia, and remains a leading cause of morbidity and mortality worldwide (5). Accurate and rapid diagnosis is crucial for the clinical management and prognosis of AMI (6). Thus, exploration of new potential biomarkers that will contribute in this direction is particularly important. Although the circulating levels of cardiac troponin proteins are currently regarded as the most prominent biomarkers for the diagnosis of AMI, measurable amounts of troponins are not usually released from damaged myocardium earlier than 4-8 $\mathrm{h}$ after the onset of symptoms $(6,7)$. In contrast, the levels of circulating plasma miRs can be measured rapidly using realtime PCR, offering two main advantages over standard antibody-based assays: increased sensitivity and specificity. Several studies have already considered circulating cardiacspecific or -enriched miRs as new biomarkers for the early diagnosis of AMI (8-12).

In fact, the vast majority of these studies have been performed in Asian populations, while limited studies from European populations are also available (12). Consequently, better validation through larger studies is required for the establishment of miRs as biomarkers in clinical practice. Based on the elegant study of Huang et al. (13) who showed that miRNA expression levels exhibit population differences, and the recorded dysregulation of two specific myocardialderived miRNAs in AMI patients $(14,15)$, we decided to further investigate their expression in a Caucasian population. Specifically, the purpose of this study was to 
Table I. Clinical characteristics of Greek AMI patients and healthy individuals.

\begin{tabular}{|c|c|c|c|}
\hline Characteristics & AMI group $(n=80)$ & Healthy group $(n=50)$ & $p$-Value \\
\hline Age (year) & $62.12 \pm 10.99$ & $59.30 \pm 9.82$ & 0.169 \\
\hline Male/Female (n/n) & $38 / 12$ & $33 / 17$ & 0.430 \\
\hline Smoking $(\mathrm{n}, \%)$ & $32(64)$ & $35(70)$ & 0.532 \\
\hline Hypercholesterolemia (n,\%) & $20(40)$ & $17(34)$ & 0.365 \\
\hline Systolic blood pressure (mmHg) & $131 \pm 26.13$ & $124 \pm 10.28$ & 0.078 \\
\hline Diastolic blood pressure (mmHg) & $77.29 \pm 13.19$ & $75 \pm 4.2$ & 0.366 \\
\hline Total Cholesterol (mg/dl) & $191.3 \pm 49.19$ & $173 \pm 31.22$ & 0.554 \\
\hline HDL (mg/dl) & $36.56 \pm 9.03$ & $34.32 \pm 7.12$ & 0.432 \\
\hline LDL (mg/dl) & $128 \pm 43.25$ & $125 \pm 25.7$ & 0.398 \\
\hline Triglyceride (mg/dl) & $152.2 \pm 79.10$ & $148 \pm 28.7$ & 0.598 \\
\hline Hypertension $(\mathrm{n}, \%)$ & $23(46)$ & $14(28)$ & 0.268 \\
\hline Glycose (mg/dl) & $158.6 \pm 122.9$ & $110.6 \pm 48$ & 0.357 \\
\hline Creatinine (mg/dl) & $13.19 \pm 31.28$ & $12.61 \pm 15.2$ & 0.207 \\
\hline Creatinine kinase-MB (CK-MB) (IU/1) & $52.42 \pm 7.15$ & $14.89 \pm 8.82$ & $<0.001$ \\
\hline Cardiac Troponin T (cTnT) (ng/ml) & $2.1 \pm 1.89$ & $0.04 \pm 0.07$ & $<0.001$ \\
\hline N-terminal Pro-brain Natriuretic Peptide (NT-proBNP) (pg/ml) & $243.74 \pm 271$ & $55.4 \pm 41.5$ & $<0.001$ \\
\hline
\end{tabular}

examine the expression of miR-208b and miR-499 in the plasma of Greek AMI patients, to determine their potential diagnostic value and to compare our results with those obtained from populations of diverse genetic backgrounds.

\section{Materials and Methods}

Subjects. Our study group consisted of 130 Greek unrelated individuals: 80 AMI patients and 50 healthy subjects who served as control. Patients' blood samples were immediately collected from individuals admitted and hospitalized in the Department of Cardiology of "KAT" General Hospital, Athens, Greece. All of the AMI patients were diagnosed for the first time and underwent a primary percutaneous coronary intervention (PCI). The criteria for diagnosis of AMI patients were based on the third Universal Definition of Myocardial infarction: 1. Acute ischemic chest pain within 24 hours; 2 . Electrocardiogram change of acute myocardial infarction (pathological Q wave, ST-segment elevation or depression) and 3. Rise of cardiac biomarkers (16).

Blood samples from AMI patients were collected into EDTA tubes prior to the PCI procedures and were immediately centrifuged (2,000 rpm, $15 \mathrm{~min}$, room temperature). The plasma generated after centrifugation was transferred to RNase-free tubes and stored at $80^{\circ} \mathrm{C}$ until further processing. The control group consisted of healthy blood donors who visited the blood donation unit of the hospital and were free of cardiac diseases, known types of cancer and autoimmune diseases, all of which might affect the expression of miRs. The study was carried out in accordance with the ethical standards of the responsible Institutional committee for human experimentation and the Helsinki Declaration, and informed consent was obtained from all participants.

MicroRNAs isolation. MiRs were extracted from plasma samples using the miRNeasy serum/plasma Kit (QiagenInc, Hilden, Germany) according to the manufacturer's instructions. In brief, miRs were purified from $200 \mu \mathrm{l}$ of plasma and eluted into $14 \mu \mathrm{l}$ of RNase-free water.
Quantification of miRNAs by Taqman qPCR assay. The quantification of miR-208b and miR-499 was determined using TaqMan ${ }^{\circledR}$ MicroRNA assays (Applied Biosystems, Foster City, CA, USA). Taqman microRNA Assays, consisted of an RNA- specific stem-looped RT primer and a TaqMan ${ }^{\circledR}$ Assay (forward and reverse primers and $\mathrm{FAM}^{\mathrm{TM}}$ dye-labeled MGB-probe).

Reverse Transcription $(R T)$ reaction. The RT reaction was performed using the TaqMan Reverse Transcription Kit (Applied Biosystems, Foster City, CA, USA). For each $15 \mu \mathrm{l}$ reaction, $5 \mathrm{ng} / \mu \mathrm{l}$ of RNA, 1X stem-loop RT, $3.33 \mathrm{U} / \mu 1$ reverse transcriptase, 0.25 $\mathrm{U} / \mu \mathrm{l}$ RNase inhibitor, $0.25 \mathrm{mM}$ dNTPs and $1 \mathrm{X}$ reaction buffer were combined and incubated at $16^{\circ} \mathrm{C}$ for $30 \mathrm{~min}, 42^{\circ} \mathrm{C}$ for $30 \mathrm{~min}$ and $85^{\circ} \mathrm{C}$ for $5 \mathrm{~min}$ in a thermocycler.

Real-Time PCR reaction. Following the RT step, $1.33 \mu$ l of the RT reaction was combined with $1 \mu$ of TaqMan Assay (20X) and 10 $\mu l$ of TaqMan ${ }^{\circledR}$ Universal PCR Master Mix, No AmpErase ${ }^{\circledR}$ UNG (PN 4324018) and $7.67 \mu \mathrm{l}$ nuclease-free water in a $20 \mu \mathrm{l}$ final volume. Quantitative real-time PCR was performed using a RotorGene 6000 system (Corbett Research, QIAGEN, Hilden, Germany) with cycling conditions of $95^{\circ} \mathrm{C}$ for $10 \mathrm{sec}$, followed by $95^{\circ} \mathrm{C}$ for $15 \mathrm{sec}$ and $60^{\circ} \mathrm{C}$ for $60 \mathrm{sec}$, for 45 cycles. RNU24 was measured as an endogenous control for the normalization of the results. Each sample was measured in triplicate. The threshold cycle $(\mathrm{Ct})$ was defined as the fraction cycle number at which the fluorescence exceeds the given threshold. $\mathrm{Ct}$ values were normalized to RNU24 using the formula $2^{-(\mathrm{Ct}[\mathrm{miR}]-\mathrm{Ct}[\mathrm{RNU} 24])}$ and the $2^{-\Delta \Delta \mathrm{Ct}}$ method was used to analyze the relative expression levels of miRs $(17,18)$.

Statistical analysis. Data were presented as total numbers, percentages, or means \pm standard deviation. The Mann-Whitney $U$ test was conducted to compare the expression of miR-208b and miR-499 between the AMI and control groups. Differences between the two groups were tested using Student's $t$-test or Fisher's exact test. Receiver operating characteristic (ROC) curve analysis was 

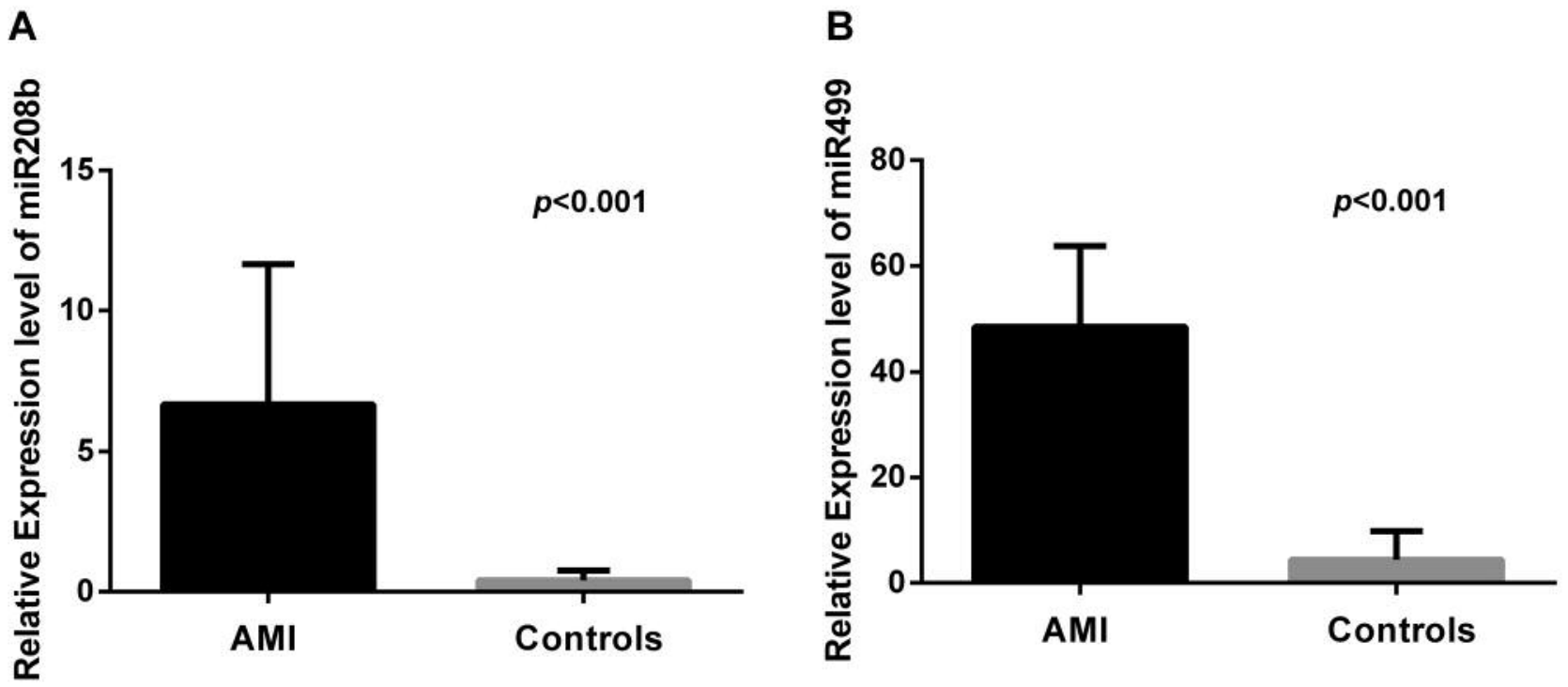

Figure 1. Plasma levels of miR208b (A) and miR499 (B) were significantly increased in the Greek AMI patients compared to healthy individuals (controls) $(p<0.001)$.

established to estimate the predictive power of the biomarkers $p$-Values $<0.05$ were considered statistically significant. Statistical analysis was carried out using GraphPad Prism 5.0 (GraphPad Software Inc., California).

\section{Results}

Clinical characteristics of the study population. The main clinical characteristics of the Greek AMI patients and healthy subjects are presented in Table I. As shown, there were no significant differences between the two groups, with regard to age, gender, smoking status and the other clinicopathological features. However, as expected, AMI patients had significantly higher creatinine kinase-MB (CK$\mathrm{MB}$ ), cardiac Troponin $\mathrm{T}$ (cTnT) and N-terminal Pro-brain Natriuretic Peptide (NT-proBNP) compared to the control group $(p<0.05)$.

Circulating miR-208b and miR-499 levels were significantly increased in Greek AMI patients. The difference of plasma miR-208b and miR-499 levels among the Greek AMI patients and healthy controls was investigated. As shown in Figure 1, the relative expression of miR-208b and miR-499 was noticeably elevated in AMI patients compared to that of controls $(p<0.001)$. Specifically, in AMI patients, plasma levels of miR-208b and miR-499 increased by 256-fold and 675-fold, respectively.

Circulating miR-208b and miR-499 expression levels as potential predictors of AMI in Greek patients. ROC curves were calculated to evaluate the predictive power of circulating miR-208b and miR-499 in Greek AMI patients. According to Figure 2A, the area under the curve (AUC) of miR-208b for the diagnosis of AMI was $0.9996[95 \%$ confidence interval $(\mathrm{CI})=0.9983-1.001, p<0.0001]$, with an optional cut-off value of 2.05 , sensitivity of $98 \%$ and specificity of $100 \%$. Similarly, the AUC of miR-499 was $0.9992(95 \% \mathrm{CI}=0.9970-1.001, p<0.0001)$ with an optional cut-off value of 18.56 , sensitivity of $98 \%$ and specificity of $100 \%$ (Figure 2B). Additionally, the AUC calculated for cTnT was $0.9400(95 \% \mathrm{CI}=0.8742-1.006, p<0.0001)$ (Figure $2 \mathrm{C})$.

\section{Discussion}

MiRs are abundantly present in a remarkably stable form, enabling their detection in the bloodstream. Many miRs demonstrate tissue- or cell-specific distribution with their circulating levels being considerably altered in individuals with various diseases. As a result, it has been suggested that miRs could serve as potential diagnostic biomarkers for a multitude of pathologies in humans.

Recent studies have revealed that aberrant miR expression profiles are associated with a variety of cardiovascular pathologies including hypertrophy, heart failure, arrhythmias and AMI (19, 20). Indeed, increased circulating levels of several myomiRs (miRNA-1, -19, -133a, -133b) which are highly expressed in skeletal muscle, as well as in the heart, were recorded (21). Moreover, the levels of certain cardiomyocyte-specific miRs in the blood and/or plasma were found modified upon initiation and evolution of AMI, 

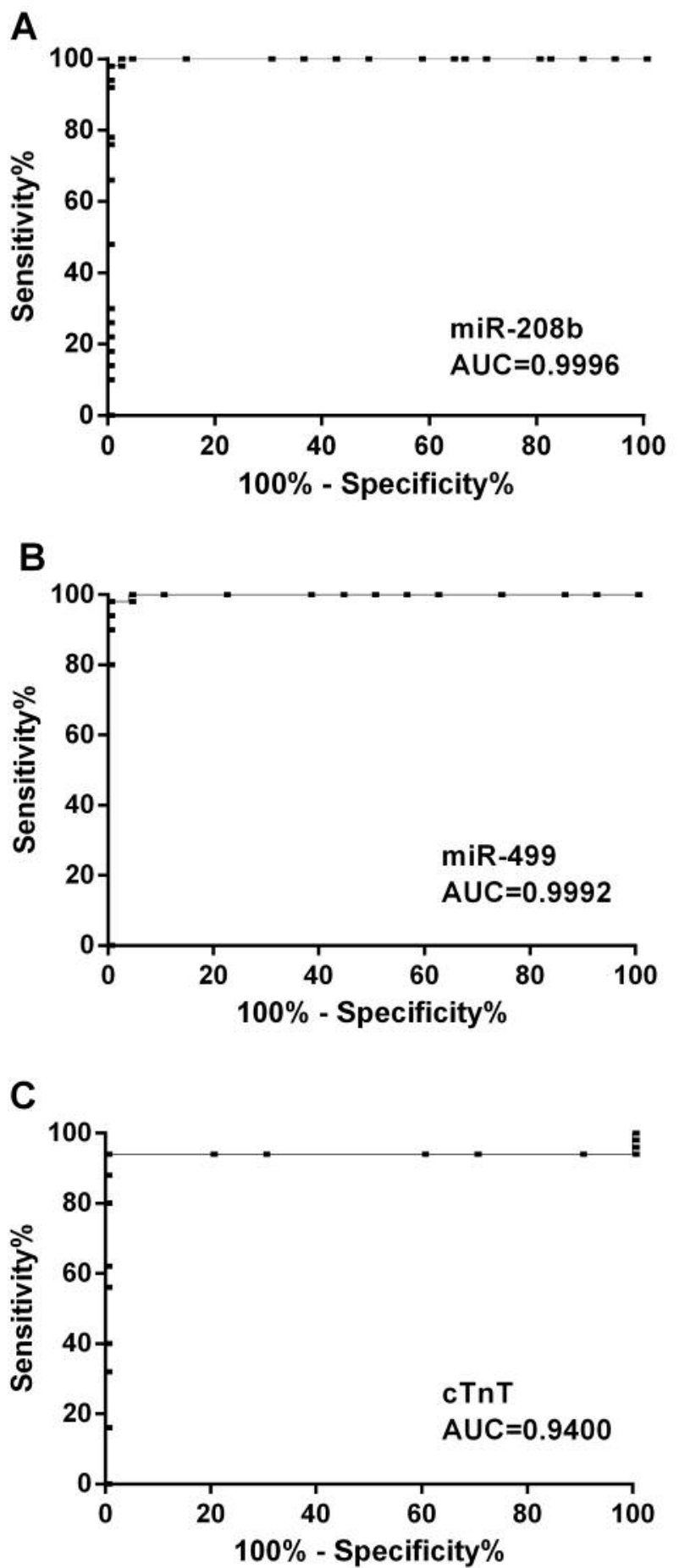

Figure 2. ROC curve analysis. The area under the curve (AUC) of miR$208 b$ (A), miR-499 (B) and cTnT (C) were 0.9996, 0.9992, and 0.9400, respectively.

verifying their utility for the early diagnosis of AMI (12). Despite all these achievements, it is essential to carry out clinical studies, including groups of individuals who have genetic differences that might influence miR expression.
To this end, we examined the differential expression of the myocyte-specific circulating miRNAs $-208 \mathrm{~b}$ and -499 in Greek AMI patients and healthy subjects. Both these miRs regulate cardiac myocyte differentiation. It is already known that cardiac damage initiates the detectable release of these miRs into circulation, making them ideal biomarkers for acute coronary syndrome $(14,15)$. Actually, the cardiac restricted miR-208b constitutes a very attractive candidate. It has been named as a "myomiR", as it is particularly expressed or found at much higher levels in cardiac tissue. MiR-208b is encoded by an intron of the alpha-myosin heavy chain gene (MYH7) and regulates the production of the myosin heavy chain in cardiomyocytes during development. In addition, it responds to stress and forms a hormonal signaling cascade in cardiac cells (22). MiR-499 is a member of the microRNA family encoded by myosin. It is expressed in myocardium and skeletal muscle in mammals, where its expression levels are low under normal physiological conditions (23). It regulates the expression of the beta myosin heavy chain, resulting in the enhancement of myocardial oxygen metabolism and tolerance (24). It has also been demonstrated that the expression levels of miR-499 exhibit a significant change in certain heart diseases, including AMI $(25,26)$.

The present study recorded a dynamic change in the expression of circulating miR-208b (256-fold) and miR-499 (675-fold) in Greek AMI patients. Importantly, blood samples at which miR expression levels were studied were collected immediately after the patient's admission at the hospital. Furthermore, ROC curve analysis displayed that circulating miR-208b (AUC: 0.9996) and miR-499 (AUC: 0.9992) exhibited similar diagnostic accuracy with the established AMI marker cTnT (AUC: 0.9400). After myocardial injury, which in some cases is notably extensive, proteins which could serve as biomarkers are released into the circulation. Unfortunately, these molecules have been characterized so far by low sensitivity, insufficient specificity or require time in order to become detectable in the biological fluids. However, rapid diagnosis and subsequently proper handling of AMI patients is crucial for their response to treatment, ensuring better survival chances. The traditional biomarkers (like cTnT and CK-MB) used in AMI management are released with delay from the damaged myocardium $(6,7)$. For all the aforementioned reasons, it is necessary to search for new AMI biomarkers to further optimize the outcome of AMI patients. Taking into account the disadvantages of the traditional biochemical markers, we propose that miR-208b and miR-499 could be used independently or ideally combinatorially for the evaluation of a patient who arrives with severe chest pain in the emergency.

Interestingly, our results from the Greek AMI population are concurrent with results from Asian populations, suggesting that miRNA-208b and miRNA-499 expression levels have not been affected by the genetic background in these specific studies $(9,11)$. Four studies so far in European populations 
correlating altered miR expression with specific types of myocardial infarction are reported in the literature: a Swedish, a Belgian, an Italian and a German. In the study of Gidlöf et al. (27), miR-208b and miR-499 increased abruptly in plasma of ST elevation myocardial infarction (STEMI) patients, but not in their urine. Furthermore, Devaux and his colleagues found miR-208b and miR-499 highly increased in MI patients and nearly undetectable in healthy controls (28). Olivieri et al. (29) showed that miR-499 mean plasma levels were high in geriatric non-ST elevation myocardial infarction (NSTEMI) patients, but miR-208a resulted undetectable. Finally, patients with a myocardial infarction (NSTEMI or STEMI) had higher circulating levels of miR-208b compared to patients with unstable angina, in the context of a large study with patients suffering from acute coronary syndrome (21). Although there are few differences between the studies and certainly the design and the exact type of cardiopathy play a role, most miRs were recorded elevated in the MI patients. Undoubtedly then, miRs $-208 \mathrm{~b}$ and -499 play crucial roles in the apoptosis of cardiomyocytes, which is involved in the pathogenesis of cardiovascular diseases; thus, supporting their clinical relevance as diagnostic biomarkers (30).

Although some miRNA genes were found to be evolutionarily conserved, it was demonstrated that the genetic background of a population, epigenetic factors, as well as the polymorphisms present in individuals, can influence their expression (13). Therefore, it is of importance to strengthen and expand previous findings by exploring miR expression in other populations as well. To the best of our knowledge, this is the first study to investigate the involvement of miRs $-208 \mathrm{~b}$ and 499 in AMI occurrences in a Greek population. In our case, the results from the Greek AMI patients are similar to those derived from the Asian and the four European populations.

\section{Conflicts of Interest}

The Authors declare that there is no conflict of interest.

\section{Acknowledgements}

The Authors thank the Hellenic Cardiological Society for its support.

\section{References}

1 Baek D, Villén J, Shin C, Camargo FD, Gygi SP and Bartel DP: The impact of microRNAs on protein output. Nature 455: 6471, 2008.

2 Small EM and Olson EN: Pervasive roles of microRNAs in cardiovascular biology. Nature 469: 336-342, 2011.

3 Skog J, Würdinger T, van Rijn S, Meijer DH, Gainche L, SenaEsteves M, Curry WT Jr., Carter BS, Krichevsky AM and Breakefield XO: Glioblastoma microvesicles transport RNA and proteins that promote tumour growth and provide diagnostic biomarkers. Nat Cell Biol 10: 1470-1476, 2008.
4 Nawar EW, Niska RW and Xu J: National Hospital Ambulatory Medical Care Survey: 2005 emergency department summary. Adv Data 386: 1-32, 2007.

5 Task Force for Diagnosis and Treatment of Non-ST-Segment Elevation Acute Coronary Syndromes of European Society of Cardiology, Bassand JP, Hamm CW, Ardissino D, Boersma E, Budaj A, Fernández-Avilés F, Fox KA, Hasdai D, Ohman EM, Wallentin L and Wijns W: Guidelines for the diagnosis and treatment of non-ST-segment elevation acute coronary syndromes. Eur Heart J 28: 1598-1660, 2007.

6 Jaffe AS, Ravkilde J, Roberts R, Naslund U, Apple FS, Galvani $\mathrm{M}$ and Katus H: It's time for a change to a troponin standard. Circulation 102: 1216-1220, 2000.

7 Thygesen K, Alpert JS and White HD: Universal definition of myocardial infarction. J Am Coll Cardiol 50: 2173-2195, 2007.

8 Margulies KB: MicroRNAs as novel myocardial biomarkers. ClinChem 55: 1897-1899, 2009.

9 Zhang L, Chen X, Su T, Li H, Huang Q, Wu D, Yang C and Han Z: Circulating miR-499 are novel and sensitive biomarker of acute myocardial infarction. J Thorac Dis 7: 303-308, 2015.

10 Liu X, Fan Z, Zhao T, Cao W, Zhang L, Li H, Xie Q, Tian Y and Wang B: Plasma miR-1, miR-208, miR-499 as potential predictive biomarkers for acute myocardial infarction: An independent study of Han population. Exp Gerontol 72: 230-238, 2015.

11 Li C, Chen X, Huang J, Sun Q and Wang L: Clinical impact of circulating miR-26a, miR-191, and miR-208b in plasma of patients with acute myocardial infarction. Eur J Med Res 20: 58, 2015.

12 Navickas R, Gal D, Laucevičius A, Taparauskaitė A, Zdanytė M and Holvoet P: Identifying circulating microRNAs as biomarkers of cardiovascular disease: a systematic review. Cardiovasc Res 111: 322-337, 2016.

13 Huang RS, Gamazon ER, Ziliak D, Wen Y, Im HK, Zhang W, Wing C, Duan S, Bleibel WK, Cox NJ and Dolan ME: Population differences in microRNA expression and biological implications. RNA Biol 8: 692-701, 2011.

14 Huang Y and Li J: MicroRNA208 family in cardiovascular diseases: therapeutic implication and potential biomarker. J Physiol Biochem 71: 479-486, 2015.

15 Xin Y, Yang C and Han Z: Circulating miR-499 as a potential biomarker for acute myocardial infarction. Ann Transl Med 4: $135,2016$.

16 Thygesen K, Alpert JS, Jaffe AS, Simoons ML, Chaitman BR, White HD, Joint ESC/ACCF/AHA/WHF Task Force for the Universal Definition of Myocardial Infarction, Katus HA, Lindahl B, Morrow DA, Clemmensen PM, Johanson P, Hod H, Underwood R, Bax JJ, Bonow RO, Pinto F, Gibbons RJ, Fox KA, Atar D, Newby LK, Galvani M, Hamm CW, Uretsky BF, Steg PG, Wijns W, Bassand JP, Menasché P, Ravkilde J, Ohman EM, Antman EM, Wallentin LC, Armstrong PW, Simoons ML, Januzzi JL, Nieminen MS, Gheorghiade M, Filippatos G, Luepker RV, Fortmann SP, Rosamond WD, Levy D, Wood D, Smith SC, Hu D, Lopez-Sendon JL, Robertson RM, Weaver D, Tendera M, Bove AA, Parkhomenko AN, Vasilieva EJ and Mendis S: Third universal definition of myocardial infarction. Circulation 126: 2020-2035, 2012.

17 Schmittgen TD and Livak KJ: Analyzing real-time PCR data by the comparative C(T) method. Nat Protoc 3: 1101-1108, 2008.

18 Livak KJ and Schmittgen TD: Analysis of relative gene expression data using real-time quantitative PCR and the 2(-Delta DeltaC(T)) Method. Methods 25: 402-408, 2001. 
19 Wang J, Liew OW, Richards AM and Chen YT: Overview of MicroRNAs in cardiac hypertrophy, fibrosis, and apoptosis. Int J MolSci 17(5): pii: E749, 2016.

20 Oury C, Servais L, Bouznad N, Hego A, Nchimi A and Lancellotti P: MicroRNAs in valvular heart diseases: potential role as markers and actors of valvular and cardiac remodeling. Int J Mol Sci 17(7): pii: E1120, 2016.

21 Widera C, Gupta SK, Lorenzen JM, Bang C, Bauersachs J, Bethmann K, Kempf T, Wollert KC and Thum T: Diagnostic and prognostic impact of six circulating microRNAs in acute coronary syndrome. J Mol Cell Cardiol 51: 872-875, 2011.

22 Liu N and Olson EN: MicroRNA regulatory networks in cardiovascular development. Dev Cell 18: 510-525, 2010.

23 Rossi AC, Mammucari C, Argentini C, Reggiani C and Schiaffino S: Two novel/ancient myosins in mammalian skeletal muscles: MYH14/7b and MYH15 are expressed in extraocular muscles and muscle spindles. J Physiol 588(Pt 2): 353-364, 2010.

24 Wilson KD, Hu S, Venkatasubrahmanyam S, Fu JD, Sun N, Abilez OJ, Baugh JJ, Jia F, Ghosh Z, Li RA, Butte AJ and Wu JC: Dynamic microRNA expression programs during cardiac differentiation of human embryonic stem cells: role for miR-499. Circ Cardiovasc Genet 3: 426-435, 2010.

25 Matkovich SJ, Van Booven DJ, Youker KA, Torre-Amione G, Diwan A, Eschenbacher WH, Dorn LE, Watson MA, Margulies $\mathrm{KB}$ and Dorn GW 2nd: Reciprocal regulation of myocardial microRNAs and messenger RNA in human cardiomyopathy and reversal of the microRNA signature by biomechanical support. Circulation 119: 1263-1271, 2009.
26 D'Alessandra Y, Devanna P, Limana F, Straino S, Di Carlo A, Brambilla PG, Rubino M, Carena MC, Spazzafumo L, De Simone M, Micheli B, Biglioli P, Achilli F, Martelli F, Maggiolini S, Marenzi G, Pompilio G and Capogrossi MC: Circulating microRNAs are new and sensitive biomarkers of myocardial infarction. Eur Heart J 31: 2765-2773, 2010.

27 Gidlöf O, Andersson P, van der Pals J, Götberg M and Erlinge D: Cardio specific microRNA plasma levels correlate with troponin and cardiac function in patients with ST elevation myocardial infarction, are selectively dependent on renal elimination, and can be detected in urine samples. Cardiology 118: 217-226, 2011

28 Devaux Y, Vausort M, Goretti E, Nazarov PV, Azuaje F, Gilson G, Corsten MF, Schroen B, Lair ML, Heymans S and Wagner DR: Use of circulating microRNAs to diagnose acute myocardial infarction. Clin Chem 58: 559-567, 2012.

29 Olivieri F, Antonicelli R, Lorenzi M, D’Alessandra Y, Lazzarini R, Santini G, Spazzafumo L, Lisa R, La Sala L, Galeazzi R, Recchioni R, Testa R, Pompilio G, Capogrossi MC and Procopio AD: Diagnostic potential of circulating miR-499-5p in elderly patients with acute non ST-elevation myocardial infarction. Int J Cardiol 167: 531-536, 2013.

30 Xin M, Olson EN and Bassel-Duby R: Mending broken hearts: cardiac development as a basis for adult heart regeneration and repair. Nat Rev Mol Cell Biol 14: 529-541, 2013.

Received December 27, 2017

Revised January 17, 2018

Accepted January 24, 2018 